\title{
Facile construction of porous magnetic nanoparticles from ferrocene-functionalized polyhedral oligomeric silsesquioxane containing microparticles for dye adsorption
}

Di Han, Zi-Qi Liu, Dai-Lin Zhou, Yi-Yi Deng, Hao Xiu, Qin Zhang, Feng Chen, and Qiang Fu*

College of Polymer Science \& Engineering, State Key Laboratory of Polymer Materials

Engineering, Sichuan University, Chengdu 610065, China

Corresponding author: Email: qiangfu@scu.edu.cn

\section{Experimental section}

Scheme S1. Synthetic route for Fc-SH.

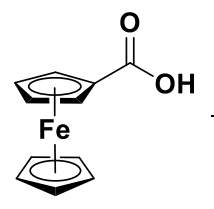

2-hydroxyethyl dissulfide DIPC, DMAP, $\mathrm{CH}_{2} \mathrm{Cl}_{2}, 0^{\circ} \mathrm{C}$<smiles>CCOCCSSCCOC(=O)c1ccccc1</smiles><smiles>CC(=O)c1ccccc1C(=O)c1ccccc1</smiles><smiles>O=C(OCCS)c1ccc(C(F)(F)F)cc1</smiles>

Synthesis of Fc-S-S-Fc. In a round bottom flask $(250 \mathrm{~mL})$ with a magnetic stirring bar, ferrocenecarboxylic acid (1800 mg, $7.83 \mathrm{mmol})$, 2-hydroxyethyl disulfide (549 mg, $3.56 \mathrm{mmol})$, DMAP (217 mg, $1.78 \mathrm{mmol})$, and anhydrous $\mathrm{CH}_{2} \mathrm{Cl}_{2}(150 \mathrm{~mL})$ were added. After complete dissolution, the solution mixture was cooled to $0{ }^{\circ} \mathrm{C}$ via ice-bath, and DIPC (1572 $\left.\mathrm{mg}, 12.46 \mathrm{mmol}\right)$ was added. 
An hour later, the mixture was warmed up to room temperature and stirred for 24 hours. Then, the solution mixture was filtered and the filtrate was concentrated to obtained the crude product. Finally, the crude product was purified by column chromatography on a silica gel by using DCM/EA (v/v = 6/1) as eluent to afford the product. Yield: $92.3 \% .{ }^{1} \mathrm{H}$ NMR (400 MHz, $\left.\mathrm{CDCl}_{3}, \mathrm{ppm}, \delta\right): 4.84$ (m, 4H, $\left.\mathrm{C}_{5} \mathrm{H}_{2}\right), 4.52\left(\mathrm{t}, 4 \mathrm{H},-\mathrm{SCH}_{2} \underline{\mathrm{CH}}_{2}-\right), 4.42\left(\mathrm{~m}, 4 \mathrm{H}, \mathrm{C}_{5} \mathrm{H}_{4}\right), 4.23\left(\mathrm{~s}, 10 \mathrm{H}, \mathrm{C}_{5} \mathrm{H}_{5}\right), 3.09$ (t, 4H, $\left.-\mathrm{SC}_{2} \mathrm{CH}_{2}-\right)$. ${ }^{13} \mathrm{C} \mathrm{NMR}\left(100 \mathrm{MHz}, \mathrm{CDCl}_{3}, \mathrm{ppm}, \delta\right): 171.59,71.43,70.61,70.18,69.83,61.94,37.61$.

Synthesis of Fc-SH. To a round bottom flask $(100 \mathrm{~mL})$ with a magnetic stirring bar, Fc-S-S-Fc (2000 mg, $3.458 \mathrm{mmol})$, DTT (640 mg, $4.15 \mathrm{mmol})$, TEA (1888 mg, $17.30 \mathrm{mmol})$ and THF (30 mL) were added, and the solution mixture was left at room temperature and stirred for $4 \mathrm{~h}$. Then, THF was removed via rotary evaporator and the crude product was dissolved into $\mathrm{CH}_{2} \mathrm{Cl}_{2}$. The organic phase was washed with water for three times and dried with anhydrous $\mathrm{Na}_{2} \mathrm{SO}_{4}$. Finally, the dried organic phase was purified by column chromatography on a silica gel, and DCM/PE (v/v = 10/1) was used as eluent to afford the product. Yield: 93.7\%. ${ }^{1} \mathrm{H} \mathrm{NMR}\left(400 \mathrm{MHz}, \mathrm{CDCl}_{3}, \mathrm{ppm}, \delta\right): 4.83\left(\mathrm{~m}, 2 \mathrm{H}, \mathrm{C}_{5} \mathrm{H}_{2}\right)$, $4.42\left(\mathrm{~m}, 2 \mathrm{H}, \mathrm{C}_{5} \mathrm{H}_{2}\right), 4.35$ (t, 2H, $\left.\mathrm{HSCH}_{2} \underline{\mathrm{CH}}_{2}-\right), 4.23\left(\mathrm{~s}, 5 \mathrm{H}, \mathrm{C}_{5} \mathrm{H}_{5}\right), 2.86$ (m, 2H, $\mathrm{HSC}_{\mathrm{H}_{2}}$ ), 1.58 (t, 1H, $\underline{\mathrm{HSCH}}_{2-}$ ). ${ }^{13} \mathrm{C} \mathrm{NMR}\left(100 \mathrm{MHz}, \mathrm{CDCl}_{3}, \mathrm{ppm}, \delta\right): 171.47,71.43,70.64,70.13,69.81,65.41,23.56$.

Instrumentation and Characterizations. The $\mathrm{NMR}$ spectra were performed in $\mathrm{CDCl}_{3}$ by using a Bruker $400 \mathrm{MHz}$ NMR spectrometer at $20^{\circ} \mathrm{C}$. Thermogravimetric analysis (TGA) was carried out on a thermo-analyzer instrument (TA Instruments Inc., USA) with a scan rate of $10{ }^{\circ} \mathrm{C} \mathrm{min}{ }^{-1}$ under air atmosphere. The morphology of particles was observed by scanning electron microscopy (SEM, JSM7500F/X-MAX50, Japan) and transmission electron microscope (TEM, FEI Talos F200x). Electron energy-loss spectroscopy (EELS) mapping was used to study the morphology and chemical composition of particles. The average sizes of particles were measured by counting over 300 particles 
via Image J software, and their coefficient of variations (CVs) were obtained according to the following equation:

$$
\mathrm{CV}=\frac{\sqrt{\sum_{i=1}^{n}\left(d_{i}-\bar{d}\right)^{2} / n-1}}{\bar{d}} \times 100 \%
$$

Where $d_{i}$ is the diameter of each particle and $\bar{d}$ is the average diameter. In the meantime, the particles size and size distribution of Fc-PCMs were further analyzed by Malvern laser particle size analyzer. Fourier transform infrared (FT-IR) spectroscopy was carried out on a Nicolet 6700 spectrometer (Nicolet, U.S.) by using the KBr disk method. X-ray photoelectron spectroscopy (XPS) was recorded on an Escalab 250Xi spectrometer (Thermo Fisher Scientific Inc., UK), employing an aluminum X-ray source. Survey scans $(0-1200 \mathrm{eV})$ were utilized to identify the surface compositions of the samples. X-ray diffraction (XRD, X' Pert Pro MPD, Philips, Netherlands) was used to characterize the crystal structure of these particles. Magnetic properties of the obtained particles were measured on a (Quantum Design) super-conducting quantum interference device (SQUID) magnetometer (MPMS-XL5, Quantum Design, USA). The diffractometer was equipped with a Nifiltered $\mathrm{Cu} \mathrm{K \alpha}$ radiation $(40 \mathrm{kV}$ and $40 \mathrm{~mA}$ ). Scans were made between Bragg angles of 2-90 . Nitrogen adsorption-desorption isothermal analysis experiments were carried out using a volumetric adsorption analyzer (Micromeritic ASAP2460, USA) at $77 \mathrm{~K}$, samples were degassed in vacuum at $473 \mathrm{~K}$ for 1 day before measurements. The Brunauer-Emmett-Teller (BET) equation was applied to calculate specific surface area of samples and the pore size distribution was evaluated from density functional theory (DFT) method. The UV/Vis adsorption spectra were measured by using a PerkinElmer Lambda $650 \mathrm{UV} /$ Vis spectrophotometer.

Adsorption experiments. Firstly, MNPs $(10 \mathrm{mg})$ was added into the MB solution $(16 \mathrm{~mL})$ with a series of concentration gradients, and the solution mixture was stirred for $3 \mathrm{~h}$. Then, MNPs was separated from the solution mixture, the MB concentrations before and after adsorption were measured 
by using a UV/vis spectrophotometer (the maximum absorption wavelength for MB is $665 \mathrm{~nm}$ ).

Notably, a linear calibration curve for MB absorbance at $665 \mathrm{~nm}$ vs [MB] was built for reference.

The adsorption capacities of particles at time $\mathrm{t}^{1}$ were calculated from the following equation:

$$
Q_{\mathrm{t}}=\frac{\left(C_{0}-C_{\mathrm{t}}\right) \times V}{m}
$$

The equilibrium adsorption capacities ${ }^{2}$ of particles were determined according to the following equation:

$$
Q_{\mathrm{e}}=\frac{\left(C_{0}-C_{\mathrm{e}}\right) \times V}{m}
$$

The removal efficiency ${ }^{2}$ of particles was calculated based on the following equation:

$$
\text { Removal efficiency }=\frac{\left(C_{0}-C_{\mathrm{e}}\right)}{C_{0}} \times 100 \%
$$

Where $Q_{\mathrm{t}}\left(\mathrm{mg} \mathrm{g}^{-1}\right)$ and $Q_{\mathrm{e}}\left(\mathrm{mg} \mathrm{g}^{-1}\right)$ represent the adsorption capacities at time $\mathrm{t}(\mathrm{min})$ and the equilibrium adsorption capacities, respectively. $C_{0}, C_{\mathrm{t}}$, and $C_{\mathrm{e}}$ are the initial concentration, the concentration at time $\mathrm{t}(\mathrm{min})$, and the equilibrium concentration, respectively. $V(\mathrm{~L})$ represents the volume of the aqueous solution and $m(\mathrm{~g})$ represents the mass of used adsorbent.

The pseudo-first-order, pseudo-second-order and intra-particle diffusion models can be expressed by using the equation (5), (6) and (7), ${ }^{3}$ respectively:

$$
\begin{aligned}
& Q_{\mathrm{t}}=Q_{\mathrm{e}}\left(1-e^{-k_{1} t}\right) \\
& \frac{\mathrm{t}}{Q_{\mathrm{t}}}=\frac{1}{k_{2} Q_{\mathrm{e}}^{2}}+\frac{\mathrm{t}}{Q_{\mathrm{e}}} \\
& Q_{\mathrm{t}}=k_{\mathrm{i}} t^{\frac{1}{2}}+C
\end{aligned}
$$

Where $k_{1}\left(\mathrm{~min}^{-1}\right), k_{2}\left(\mathrm{~g} \cdot \mathrm{mg}^{-1} \cdot \mathrm{min}^{-1}\right)$ and $k_{\mathrm{i}}\left(\mathrm{mg} \cdot \mathrm{g}^{-1} \cdot \mathrm{min}^{-0.5}\right)$ are the adsorption rate constant of the pseudo-first-order, pseudo-second-order and intra-particle diffusion models, respectively. $C\left(\mathrm{mg} \cdot \mathrm{g}^{-1}\right)$ is a constant.

The obtained equilibrium adsorption results can be analyzed by fitting against the Langmuir (Eq. 
(8)) and Freundlich isotherm models (Eq. (9)). ${ }^{4}$

$$
\begin{gathered}
\frac{C_{\mathrm{e}}}{Q_{\mathrm{e}}}=\frac{1}{K_{\mathrm{L}} Q_{\mathrm{m}}}+\frac{C_{\mathrm{e}}}{Q_{\mathrm{m}}} \\
\ln Q_{\mathrm{e}}=\ln K_{\mathrm{F}}+\frac{1}{n} \ln C_{\mathrm{e}}
\end{gathered}
$$

where $Q_{\mathrm{m}}$ is the maximum adsorption capacity, $K_{\mathrm{L}}\left(\mathrm{L} \cdot \mathrm{mg}^{-1}\right)$ and $K_{\mathrm{F}}\left(\mathrm{mg}^{(1-(\mathrm{n}-1))} \cdot \mathrm{L}^{(\mathrm{n}-1)} \cdot \mathrm{g}^{-1}\right)$ are the adsorption equilibrium constant of Langmuir and Freundlich isotherm models, respectively. And $K_{\mathrm{F}}$ can represent the adsorption capacity. $n$ is the empirical parameter which is related to adsorption strength.

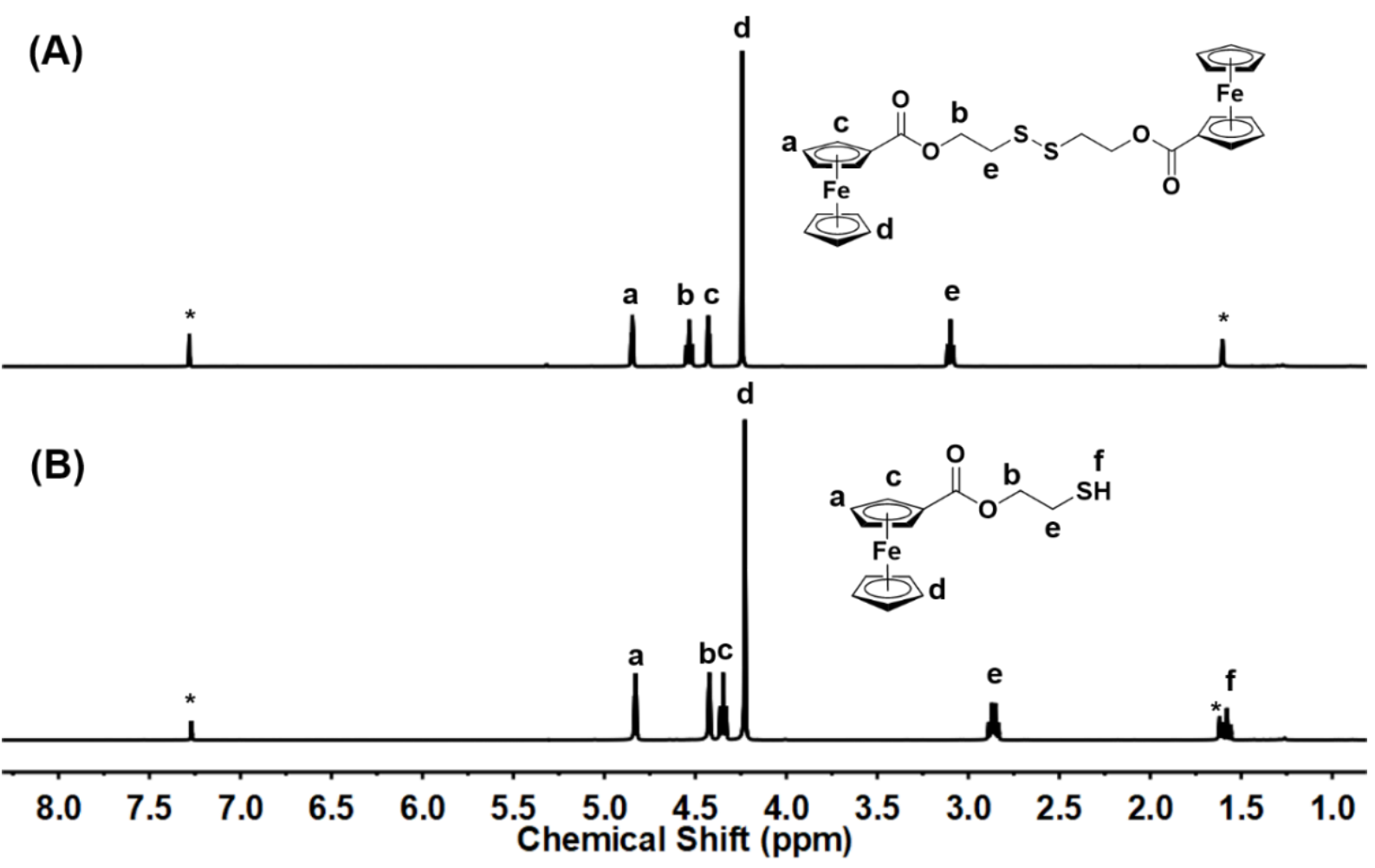

Figure S1. ${ }^{1} \mathrm{H}$ NMR spectra of (A) Fc-S-S-Fc and (B) Fc-SH. The asterisk peaks represent $\mathrm{CDCl}_{3}$ or $\mathrm{H}_{2} \mathrm{O}$. 


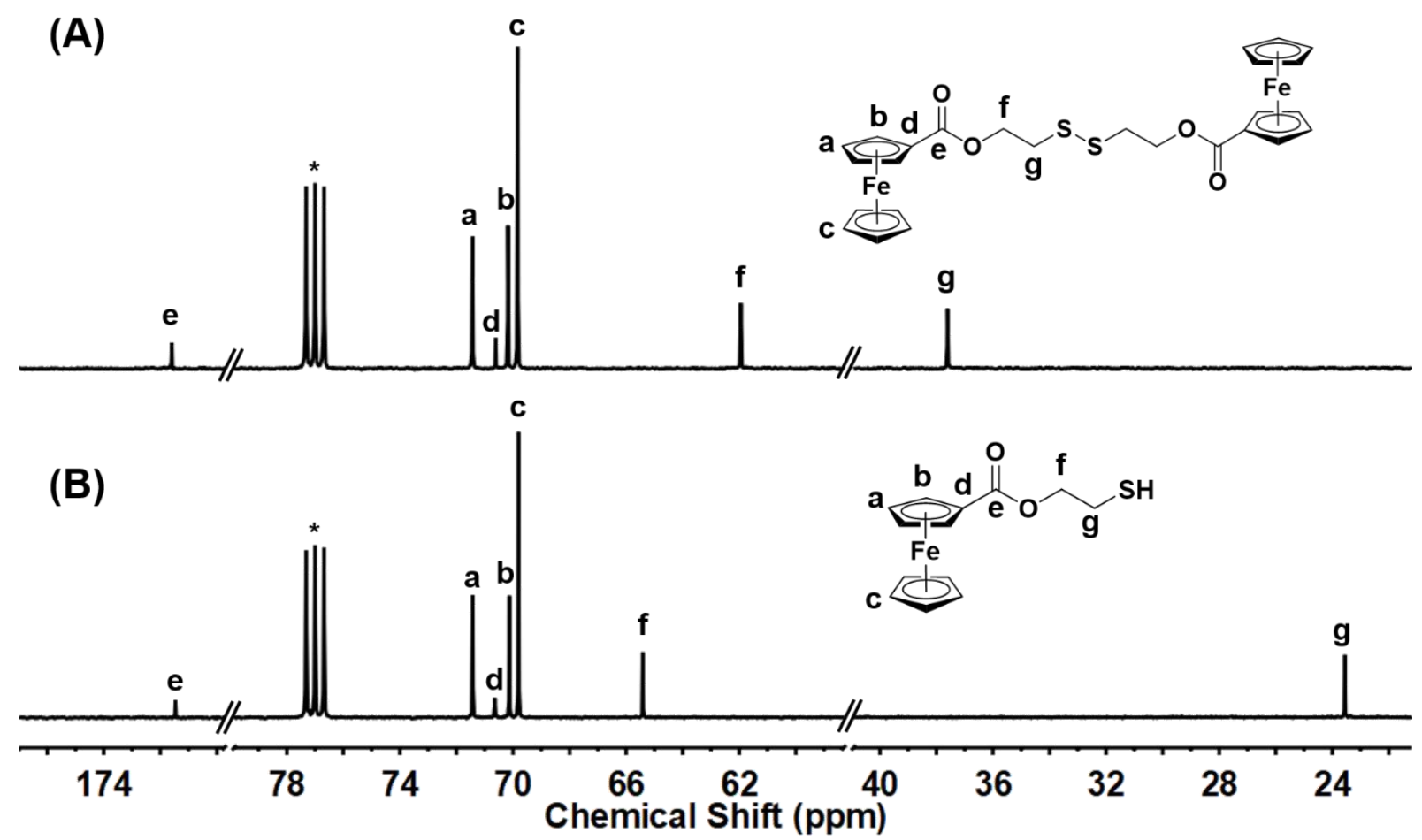

Figure S2. ${ }^{13} \mathrm{C}$ NMR spectra of (A) Fc-S-S-Fc and (B) Fc-SH. The asterisk peaks represent the $\mathrm{CDCl}_{3}$.

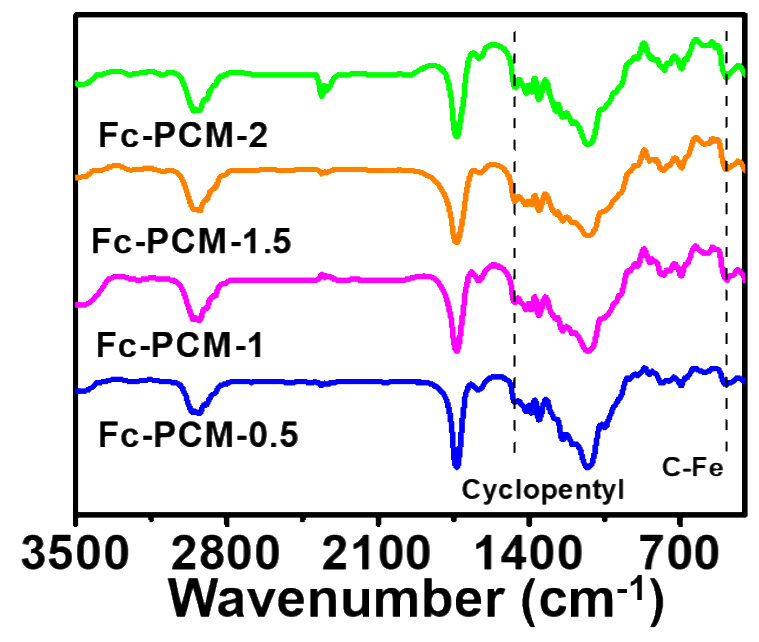

Figure S3. FT-IR spectra of Fc-PCMs. 


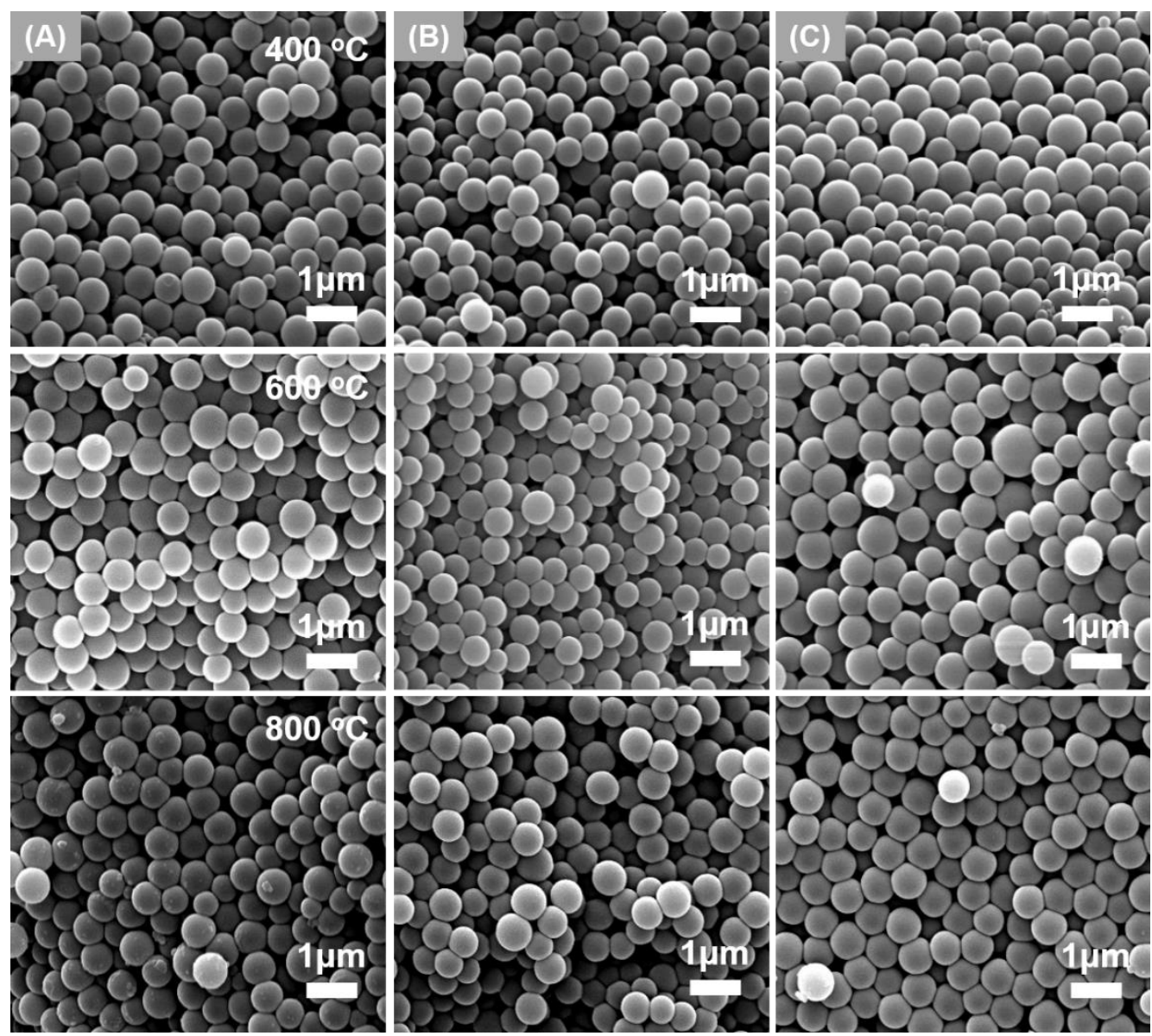

Figure S4. SEM images of (A) $c$-Fc-PCM-0.5, (B) $c$-Fc-PCM-1, and (C) $c$-Fc-PCM-1.5. (Top: calcination at $400{ }^{\circ} \mathrm{C}$ for $2 \mathrm{~h}$; middle: calcination at $600{ }^{\circ} \mathrm{C}$ for $2 \mathrm{~h}$; bottom: calcination at $800{ }^{\circ} \mathrm{C}$ for 2h).

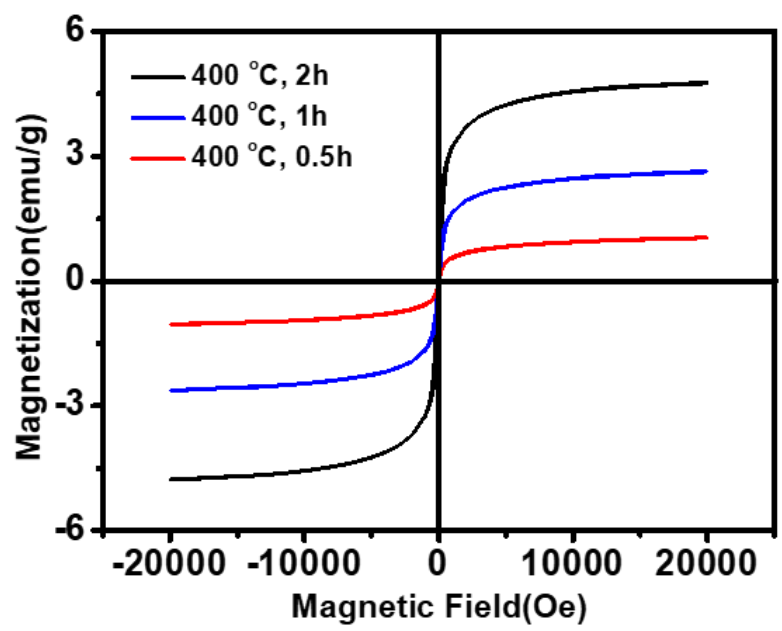

Figure S5. The effect of calcination time for the magnetization $(M)$ versus magnetic field $(H)$ at 25 ${ }^{\circ} \mathrm{C}$ of $c$-Fc-PCM-2. 


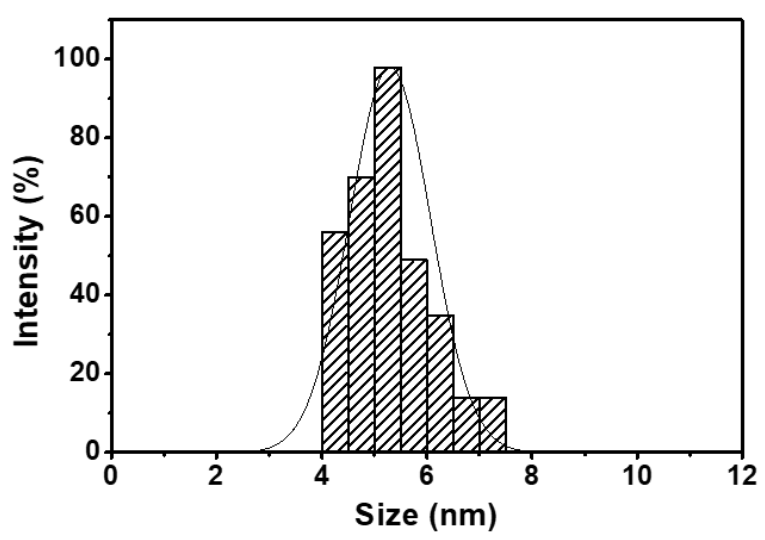

Figure S6. The size of $\mathrm{Fe}_{3} \mathrm{O}_{4}$ crystals inside the large particle measures from TEM image.
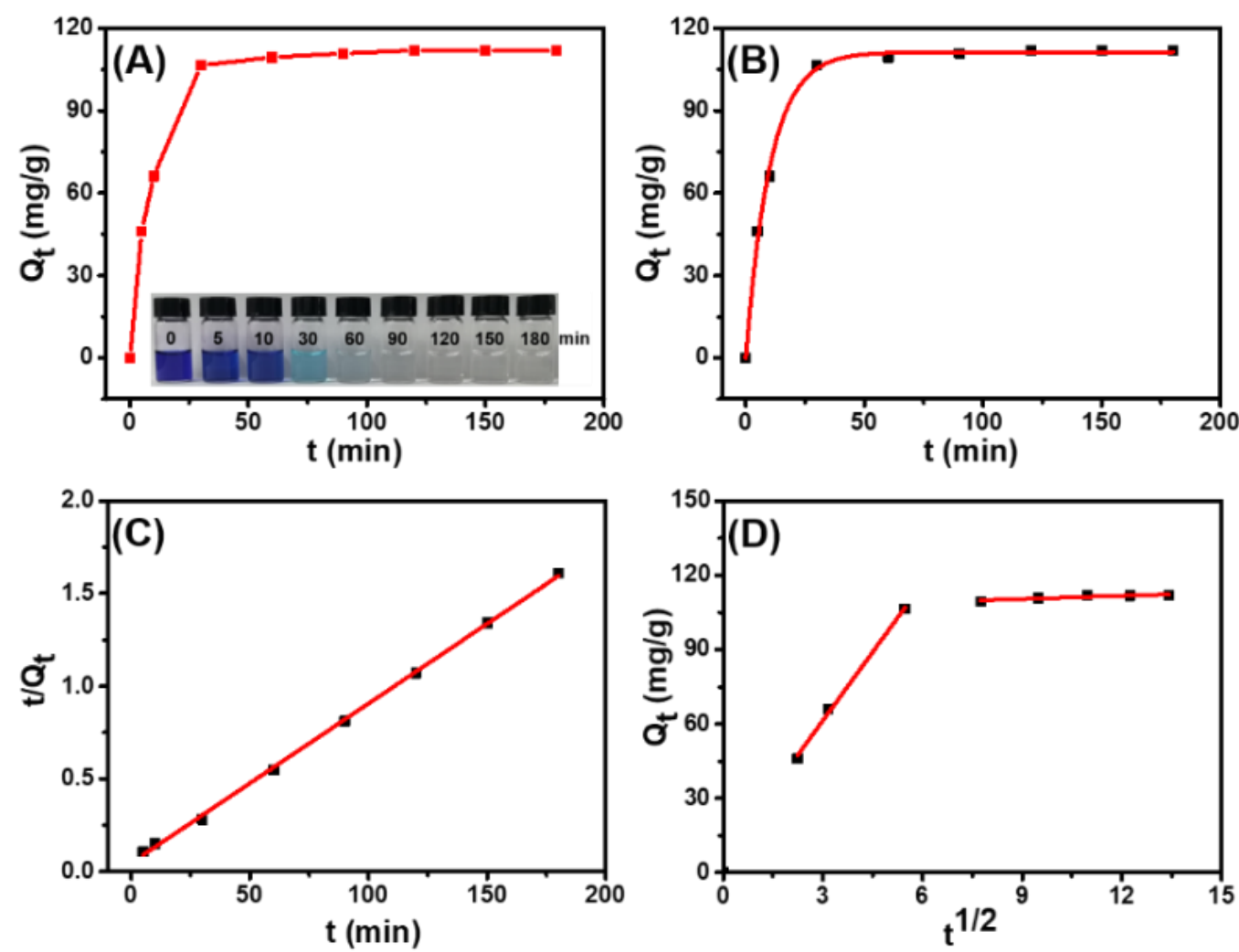

Figure S7. (A) Effect of contact time on MB adsorption capacity, (B) pseudo-first-order, (C) pseudosecond-order and (D) intra-particle diffusion models for the adsorption of MB onto $c$-Fc-PCMs at $25{ }^{\circ} \mathrm{C}$. 
Table S1. Element content calculated from XPS data (experimental) and monomer feeding ratio (theoretical).

\begin{tabular}{ccccccc}
\hline & Sample & $\mathrm{C}(\mathrm{wt} \%)$ & $\mathrm{O}(\mathrm{wt} \%)$ & $\mathrm{Si}(\mathrm{wt} \%)$ & $\mathrm{S}(\mathrm{wt} \%)$ & $\mathrm{Fe}(\mathrm{wt} \%)$ \\
\hline & Fc-PCM-0.5 & 50.09 & 27.88 & 12.57 & 8.57 & 0.89 \\
& Fc-PCM-1 & 48.29 & 27.64 & 12.96 & 9.31 & 1.79 \\
Experimental & Fc-PCM-1.5 & 48.92 & 26.40 & 11.88 & 9.91 & 2.62 \\
& Fc-PCM-2 & 51.36 & 24.74 & 11.69 & 9.08 & 3.13 \\
& Fc-PCM-0.5 & 46.10 & 31.31 & 9.96 & 11.39 & 1.25 \\
& Fc-PCM-1 & 46.76 & 30.23 & 9.62 & 10.99 & 2.40 \\
& & & & & & \\
& Fc-PCM-1.5 & 47.37 & 29.22 & 9.30 & 10.62 & 3.49 \\
& Fc-PCM-2 & 47.95 & 28.27 & 9.00 & 10.28 & 4.50 \\
\hline
\end{tabular}

Table S2. Effect of calcination temperature on the elemental composition (obtained from XPS results) of Fc-PCM-2 (calcination for $2 \mathrm{~h}$ ).

\begin{tabular}{cccccc}
\hline Temperature $\left({ }^{\circ} \mathrm{C}\right)$ & $\mathrm{C}(\mathrm{wt} \%)$ & $\mathrm{O}(\mathrm{wt} \%)$ & $\mathrm{Si}(\mathrm{wt} \%)$ & $\mathrm{S}(\mathrm{wt} \%)$ & $\mathrm{Fe}(\mathrm{wt} \%)$ \\
\hline As-prepared & 51.36 & 24.74 & 11.69 & 9.08 & 3.13 \\
400 & 28.10 & 39.34 & 22.51 & 1.74 & 8.31 \\
600 & 2.76 & 49.78 & 42.10 & 1.28 & 4.08 \\
800 & 1.30 & 51.17 & 45.26 & 1.13 & 1.14 \\
\hline
\end{tabular}

Table S3. The kinetic parameters of adsorption of MB onto $c$-Fc-PCMs according to pseudo-firstorder and pseudo-second-order models.

\begin{tabular}{cccccccc}
\hline \multicolumn{3}{c}{ Pseudo-first-order } & \multicolumn{5}{c}{ Pseudo-second-order } \\
\hline $\mathrm{k}_{1}$ & $\mathrm{q}_{\mathrm{e}}$ & $\mathrm{q}_{\mathrm{e}}$ & $\mathrm{R}^{2}$ & $\mathrm{k}_{2}$ & $\mathrm{q}_{\mathrm{e}}$ & $\mathrm{q}_{\mathrm{e}}$ & $\mathrm{R}^{2}$ \\
$\left(\mathrm{~min}^{-1}\right)$ & $(\mathrm{cal}).\left(\mathrm{mg} \cdot \mathrm{g}^{-1}\right)$ & $(\mathrm{exp}).\left(\mathrm{mg} \cdot \mathrm{g}^{-1}\right)$ & & $\left(\mathrm{g} \cdot \mathrm{mg}^{-1} \cdot \mathrm{min}^{-1}\right)$ & $(\mathrm{cal}).\left(\mathrm{mg} \cdot \mathrm{g}^{-1}\right)$ & $(\mathrm{exp})\left(\mathrm{mg} \cdot \mathrm{g}^{-1}\right)$ \\
0.097 & 111.37 & 111.90 & 0.9978 & 0.00158 & 116.28 & 111.90 & 0.9991 \\
\hline
\end{tabular}


Table S4. The kinetic parameters of adsorption of MB onto $c$-Fc-PCMs according to intra-particle diffusion model.

\begin{tabular}{cccccc}
\hline \multicolumn{5}{c}{ Intra-particle diffusion } \\
\hline $\begin{array}{c}\mathrm{K}_{\mathrm{i} 1} \\
\left(\mathrm{mg} \cdot \mathrm{g}^{-1} \cdot \mathrm{min}^{-0.5}\right)\end{array}$ & $\mathrm{C}_{1}$ & $\mathrm{R}_{1}{ }^{2}$ & $\mathrm{k}_{\mathrm{i} 2}$ & $\mathrm{C}_{2}$ & $\mathrm{R}_{2}{ }^{2}$ \\
18.42488 & 6.08144 & 0.9950 & 0.42682 & 106.6121 & 0.7318 \\
\hline
\end{tabular}

Table S5. Parameters calculated from the Langmuir and Freundlich isotherm model for the adsorption of MB by $c$-Fc-PCMs.

\begin{tabular}{|c|c|c|c|c|c|c|c|}
\hline \multicolumn{5}{|c|}{ Langmuir isotherm } & \multicolumn{3}{|c|}{ Freundlich isotherm } \\
\hline $\begin{array}{c}\mathrm{Q}_{\mathrm{m}} \\
(\mathrm{exp} .)\left(\mathrm{mg} \cdot \mathrm{g}^{-}\right. \\
\left.{ }^{1}\right)\end{array}$ & $\begin{array}{c}\mathrm{Q}_{\mathrm{m}} \\
\left(\mathrm{mg} \cdot \mathrm{g}^{-1}\right)\end{array}$ & $\begin{array}{c}\mathrm{K}_{\mathrm{L}} \\
\left(\mathrm{L} \cdot \mathrm{mg}^{-1}\right)\end{array}$ & $\mathrm{R}^{2}$ & $\mathrm{R}_{\mathrm{L}}$ & $\begin{array}{c}\mathrm{K}_{\mathrm{F}} \\
\left(\mathrm{mg}^{(1-(\mathrm{n}-1))} \cdot \mathrm{L}^{(\mathrm{n}-1)} \cdot \mathrm{g}^{-1}\right)\end{array}$ & $\mathrm{n}$ & $\mathrm{R}^{2}$ \\
\hline 452 & 456 & 0.127 & 0.9972 & $0.0097-0.2079$ & 145.64 & 5.10 & 0.9852 \\
\hline
\end{tabular}

\section{References}

(1) Glasstone, S.; Laidler, K. J.; Eyring, H. The Theory of Rate Processes; the Kinetics of Chemical Reactions, Viscosity, Diffusion and Electrochemical Phenomena; McGraw-Hill Book Company: 1941.

(2) Yang, X.; Liu, H., Diphenylphosphine-Substituted Ferrocene/Silsesquioxane-Based Hybrid Porous Polymers as Highly Efficient Adsorbents for Water Treatment. ACS Appl. Mater. Interfaces 2019, 11 (29), 26474-26482.

(3) Liu, Y.; Chen, M.; Yongmei, H., Study on the adsorption of $\mathrm{Cu}$ (II) by EDTA functionalized $\mathrm{Fe}_{3} \mathrm{O}_{4}$ magnetic nano-particles. Chem. Eng. J. 2013, 218, 46-54.

(4) Liu, J.; Wong, L. M.; Wong, L. H.; Chiam, S. Y.; Li, S. F. Y.; Ren, Y., Immobilization of dye pollutants on iron hydroxide coated substrates: kinetics, efficiency and the adsorption mechanism. $J$. Mater. Chem. A 2016, 4 (34), 13280-13288. 